\title{
Puugipask, mahasadanud pilved ja taevased seened
}

\author{
Aivar Jürgenson
}

Märganud sellist pealkirja, võib lugeja nõutust tunda. Puuk oma väljaheitega, lendavad seened ja meteoroloogiline ilming talle täiesti sobimatus keskkonnas - peab omama head fantaasiat, et selliseid eriskummalisi asju vaimusilma ette manada. Ja kui kõik need raskesti ettekujutatavad asjad on korraga ühes lauses koos, siis peab tunnistama, et tegemist on arusaamatu lausega. Seda, et ühisnimetaja puudub, märkab ju kohe.

Tegelikult pole asi sugugi nii hull, sest otsitud ühisnimetaja on olemas. Nii puugipasa kui maised pilved võime bioloogilist lahterdamisviisi kasutades seente hulka paigutada. Bioloogilise liigi taevasse lokaliseerimise taga on aga rahvausk. Niisiis on otsitud ühisnimetajaks seened usundis ja seenejuttu siinkohal ajamegi. Enne asja juurde asumist tuleb siiski teha üks täpsustus, nimelt eristada seeni seentest. Kui sügisel seenele minekust juttu tehakse, siis mõeldakse ikka korvi ja noaga metsa minemist, et puravikke, riisikaid ja teisi kübaraga seeni korjata. St. tavalises keelepruugis seostuvad mõistega seen eelkõige kübarseened. Seened on eelkõige need loodusobjektid, mis metsas jala peal seisavad ja end korjama meelitavad. Kui seenele minnakse, siis mõeldakse ikka metsa minemist. Kui seenele saadetakse, siis mõeldakse ka metsa või metsapooleolemist.

Seened, mida siinkohal vaatleme, on aga limaseened. Limaseeni on rahvausundis sageli seostatud millegi ebamaise või üleloomulikuga: nii on puugipask olnud rahva kujutluses arvatud nõia tekitatuks või saadetuks, pilvepala aga olevat sootuks taevast päritolu. Küllap seepärast on neisse kui erilist väge sisaldavatesse loodusbjektidesse suhtutud suure respektiga: ühelt poolt on nad kardetavad, teisalt võib nendega oskuslikult ümber käies nii- või naasuguseid kunsttükke teha.

\section{Puugipask}

Märkimisväärse koha eesti usundis on hõivanud limaseen Fuligo septica, mida on seostatud puugi või koguni nõiaga. Tegemist on maailma suurima limaseenega, mille viljakeha võib kasvada üle $30 \mathrm{~cm}$ suureks (Kastanje 1995: 48). Rahvasuus tuntakse teda (eelkõige Läänemaal ja Saaremaal) puugipasa, puugisita, harva nõiapasa, aga paikkonniti ka raganasita või -pasa (peamiselt Häädemeeste ümbruses), harvem lehmasita (Saaremaal), koerajäti (Kihnus), kratisita (Hiiumaal ja Kihnus), päärapasa (Läänemaal ja Hiiumaal), peerapasa, muugasita nimetuse all. Sageli on ta kollane, kuid esineb ka teisi toone, sagedamini valget, mõne teate järgi

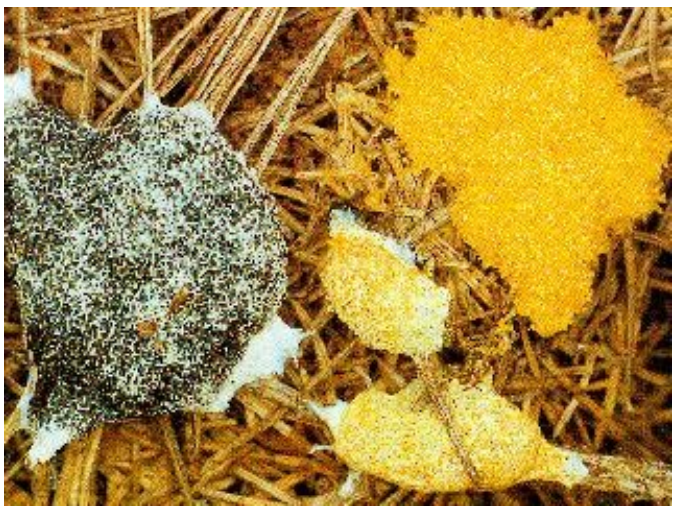

Puugipask (Fuglio septica) on eriti silmatorkav vihmajärgsetel päevadel ka halli ja punast. Värvus ei varieeru siiski nii palju kui pilvepala puhul.

Üldiselt on iseloomustused suhteliselt ebamäärased, siinkohal võiks välja tuua järgnevad kirjeldavad repliigid: kännu peal kollane laik või lärakas (Häädemeeste), valge sülditaoline (Hääde- 
meeste), vaht (Reigi, Karja, Sangaste), lima (Kihelkonna), seina pääl suured pehmed plärakad (Käina), nagu pehme või (Kullamaa), kollane vedel hallitus, mis on vahel sõrme otsa suuruste laigukestena välisseina palkidel (Kirbla), pudrusarnane (Saarde). Vahel on puugipaska ka otse seeneks nimetatud: kollane tatikas (Kullamaa), kollakas-valge seenetus puu peal (K.-Jaani), lödijas käsnataoline seen (Püha), seen (Kullamaa), väike valge seenekene (Põltsamaa).

Puugipasa leidmisega on seotud erinevad kujutelmad. Esimeses järjekorras nimetatagu uskumust, et kui puugi või krati kõht vara (piima) vedades liiga täis saab, siis ta jätab endast maha jälje, puugipasa (Loorits 1949: 296). Tavaliselt põletati see ära (ERA II 188, 323(74) < Käina khk., Nõmme k. - E. Ennist (1938), mille tagajärjena usuti puugikskäijal juhtuvat mingi õnnetus, näiteks tekkisid tal seedehäired vm. Hädast lahtisaamiseks pidi viimane oma ohvri käest midagi saama, sageli sööki (ERA II 168, 43(1) < Mustjala khk., Järise k.- A. Toomesalu (1937); E 77380(17) < Jämaja khk. - A. Kuldsaar (1931).

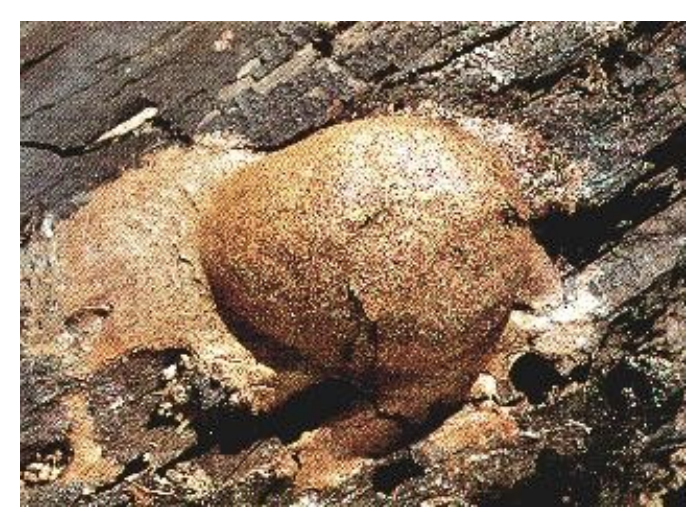

Rahvauskumuste järgi võib puugipask palju kahju tekitada

Teise suurema rühma moodustavad teated, mille järgi puugipaska saatvat nõid kahju tekitamiseks: ta toimetab raganasita käidavale kohale ohvri maja lähedusse. Kui mõni loom või inimene seda puutub, juhtub talle õnnetus (ERA II 42, 317 < Häädemeeste khk; E 78624 (1) < Saarde khk). Kannatada võib mitte puugipasa lõhkuja, vaid see, kelle nime peale ta on saadetud (KKI, KSL $<$ Häädemeeste khk - N. Saate; ERA II, 60, $514(85)<$ Häädemeeste khk - M. Martinson (1933)). Kui aga puugipask terveks jäi ja ise ära kuivas, siis õnnetust ei juhtunud. Seepärast soovitati temasse mitte puutuda või võeti ta ettevaatlikult tervena üles ja visati tulle (ERA II 69, 214(16) < Häädemeeste khk - M. Martinson (1934)). Mõnede teadete kohaselt tulle visatud raganasitt plahvatab (ERA II 21, 493 (23) < Häädemeeste khk - L. Lepp (1929); ERA II 21, 473 (1) < Häädemeeste khk - L. Lepp (1929)).

Ühe teate järgi on seina pealt leitud päärapask kolde kohale naelutatud. Toime olevat sama kui põletamise puhul (H II 16, 790 (3) < Risti khk - J. Holts (1889)). Arvamuse kohaselt pole iga kord piisanud lihtsast tulleviskamisest, vaid puugipask suletud lepapakku puuritud auku ning seejärel põletatud (H, Mapp $926<$ Riia < Saaremaa; E 80888 (3) < Karja khk; ERA II 289, 513 (63) < Jaani khk., Hindu k. - A. Vinkel (1940)). Ühe teate järgi pandud puugipaska kondi sisse pihlakase prundi alla ja seejärel põletatud (H IV 5, 47/8(30) < Jüri khk - K. Põldmäe (1895))

Leitud raganasitale tulnud mõne teate kohaselt ühe joonega tõmmata viiskand terava noaga keskele, siis näed, nende aavade sisse tuleb puhas veri, selge punane veri-- siis sii õnnetus läheb tagasi, sellel saatjal, ta saab isi kätte, mis teisele suuvis. (KKI KSL < Häädemeeste khk - M. Mäesalu (1980)). Sarnane on järgmine teade: Pidi tooma poest uus nuga ja puuga sitt katki leikama, siis pidi puugal perse katti olema. Nii otsiti puuke üles. Kes vana naine siis oetesse maha jäi, see oli puugaks käind (ERA II 157, 159/60(14) < Anseküla khk, Salme v - A. Raadla (1937)).

Kättemaks ragana saatjale toimus muuhulgas järgmiselt: kui mõni loom ragana tõttu suri, pidi sellel loomal kõrvad ära lõikama ja ahju viskama - sellest surid ka raganategijal loomad (ERA II 42, 317 $<$ Häädemeeste khk - N. Kallas (1932)). 
Ennetava maagiana toodi puugipaska loomalauda ukse ette, et vältida loomaõnnetust (RKM II 17, 456 (4) < Tõstamaa khk).

Puugisita tõrjet kirjeldab ka järgmine teade: Ä̈̈demeste köstre emandal olnu ükskord raganasitt just uksepaku pääl. Tema võtnu kirve ja löönu sita risti pooleks. Kohe olnu ta oma lehmal lautas sellaluu ka pooleks (ERA II 21, 317 (18) < Häädemeeste khk - L. Lepp (1929)).

Kontaktmaagia ilmneb ka järgmise loo puhul: Oli nõid, kutsuti Tohtre-Jaan. Kord viib puugisitta ühe talu karjamaale. Kavatsus seega loomadele paha teha. Sulane näinud. Laseb püssiga pungisitale. Kohe Tohtre--Jaanil hobune haigeks. See ütlema, küll ta teadvat, kes seda teinud.(ERA II 336/7 (4) < Saarde khk - Ed. Kask).

Lugudes puugipasast esineb vaheldumisi ja kohati segunenult mitu motiivi: tegemist on kellegi valmistatud puugiga, inimene käib puugiks vara vedamise eesmärgil, nõid saadab puugi muud kurja soovides. Tõrjeks on puugipask tavaliselt põletatud, aga ka seinale naelutatud, teda on terariistaga raiutud, nõgestega pekstud või püssist tulistatud.

\section{Pilvetükid}

Pilvetükid või pilvepala on rahvusvaheliselt levinud nähtus, mida tuntakse eesti, läti, liivi, vadja, soome ja rootsi usundis, ka Saksamaal, kuid seal peetakse neid mahalangenud tähtede kildudeks.

Asjatundlik lugeja ilmselt sooviks siinkohal leida bioloogilise liigi kohta oskussõna koos ladinakeelse vastega. Põhjus, miks ta seda siit ei leia, on lihtne: selle sültja olluse puhul pole alati selge, kas liigitada teda seente või vetikate hulka. Rahvaluuleuurijate näpuharjutused bioloogide töömail on vahel paraku segadusttekitavad. M. J. Eisen nimetab pilvetükke seenteks: "Tõepoolest kuuluvad pilvetükid seente hulka (Tremella Nostoc L.), mis kuiva ajal peaaegu nägematud, pärast vihma aga paisuvad ja süldisarnase näo omandavad." (Eisen 1926: 59). M. J. (Lycogala conicum) on tavapäraselt Eisenist alates on vist küll kõik rahvaluule uurijad, kes hallikaspruun ilusa musta ornamendiga selle küsimusega tegelenud, neid järjekindlalt seente hulka arvanud. On see aga alati põhjendatud? Nii mõneski tekstis võib kirjelduse järgi ära tunda hoopis vetikad. Kindlasti on vetikatega tegemist O. Looritsa poolt kirjeldatud nähtuse puhul. Käsitledes pilvetükkide teemat liivi usundis, kirjutab ta: "Aga neid nimetatakse ka merepilved ehk veepilved, tulevad ka merest randa otsekui konnakoed, eriti kevadeti mere õitsemise aegu on neid väga palju." (Loorits 1926: 59-60).

Kui enamikul juhtudest on tegemist limaseentega - põhiliselt nimetatakse liiki Tremella nostoc, siis alati pole konkreetse liigi määramine sugugi kerge: traditsiooni dominandina hõlmab pilvepala erinevaid bioloogilisi liike. Eestist pärinevate teadete järgi võivad pilvetükid olla valged (Räpina, Põlva), sinised (Simuna, Järva-Madise), kollased (Simuna, Kolga-Jaani), hallid (Võnnu), rohekad 
(Võnnu), üksikteate põhjal on pilvepala alguses valkjassinine, hiljem vananedes muutub kollakaks (Kolga-Jaani). On selge, et pilvetükkideks nimetatakse erinevaid bioloogilisi liike. Küsimusele, millise limaseenega igal üksikjuhul konkreetselt tegemist on, ei saa tegelikult üheselt vastata. Erast Parmasto väide, et teised limaseened pole usundis erilist tähelepanu pälvinud, vajab mu meelest täpsustamist. Näiteks nimetab ta näsaroostet (Parmasto 1988: 321). Tegelikult on võib olla sedagi limaseent peetud pilvetükiks. Olen leidnud rahvaluule arhiivist teate, millest selgub, et pilvetükke usuti asuvat kadakaokstel (Saareste, MK Tikerpuu (574) < Pühalepa khk), mis on tüüpiline näsarooste kasvukoht. Vanarahva printsiibid bioloogiliste liikide lahterdamisel ei olnud nii ranged kui bioloogidel.

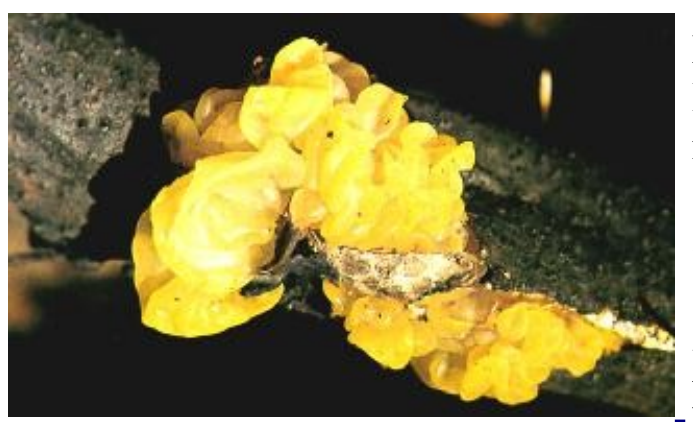

Mõnedki limaseene liigid arenevad vaid väga niiske ilmaga. Üks ilusamaid on Tremella

Ka Lycogala epidendrumi puhul, mis arhiiviteateil esinevad paikades, mida bioloogid tunnevad hundipiima kasvukohtadena, võiks oletada seost pilvepalaga. Hundipiim kujutab endast 3-15 mm läbimõõduga oranzhroosasid kerajaid moodustisi. Erast Parmasto andmeil esineb hundipiim maist hilissügiseni kändudel, rontidel, aiapostidel jne. Kesta katkivajutamisel tungib neist välja eredat värvi piimjas plasma. Parmasto arvates on nimetus hundipiim ilmselt puhtkirjakeelne: lycos - hunt, gala piim (Parmasto 1987: 368). Huvitav on siinkohal märkida, et rahvasuus on pilvetükke nimetatud hundiokseks (ERA II 12, 190 (56) < Simuna khk - R. Viidebaum (1928-29)).

Samas ei saa välistada ka hundipiima ja puugipasa (vrd piima maha jätva puugi) võimalikke seoseid. Teateis puugipasast ja pilvetükkidest on sarnast: nii nagu puugipasast, hoiti eemale ka pilvetükkidest, et neist ei saaks haigust. Nii nagu puugipask, põletati ka pilvetükid kahju hävitamiseks ära (E 8 12, 25 (73) < Kadrina khk - M. J. Eisen).

Pilvetükkide konsistentsi kohta on järgmised iseloomustavad teated: pilvetükk on nagu sült (Sangaste), hapupiim (Helme), hüübinud lihaleem (Puhja), vasikasült (Varbla). Arvamus, et pilved koosnevad tahkest ainest, on juhtinud huvitavate seletusteni: pilvede tahkusega seletatakse, kuidas mõni inimene on pilve peal käinud ja kuidas Kõu ja Pikker pilve peal sõidavad või kuidas Hans lubas Vanapagana nuia pilve peale visata (E $7591<$ Ambla khk - O. Hinzenberg). Pilvede vastakuti jooksmisel hõõrduvat alumise pilve krobeline kaas vastu ülemist pilve ja sellest tulevat müristamine (ERA II 153, 816 (72) < Haljala khk - H. Länts (1937)). Pilvetükkide koostise põhjal usuti kohati, et pilvedki koosnevad süldisarnasest vrd seenelaadsest ainest: Taevas lööb seenetama/ akkab vihma tulema// al'l' pilvevinu üle taeva// taevas on seenetand (LS < Nissi khk, Laitse-Aruküla - K. Meikop (1932)). Arvati, et pilved jooksevad edasi lõngadel, millelt kogemata tükke pudeneb, eriti müristamise ajal (Hurt 1899: 7)

Hurda tekstile sekundeerib teade Saaremaalt: Ühekorra kukkund uss põllule pilvetüki seest, keegi pole tohtind ää tappa, suures ringis olnd maas (ERA II 158, 449/50 (29) < Mustjala khk - A. Ahurand (1937)).

Taevase päritolu tõttu peetakse pilvetükke pühaks ja võetakse sisse ravimina mitmete haiguste puhul (Loorits 1949: 437). Pilvetükid on ravimiks halltõve, pistete, soetõve, soolatüügaste, sammaspoole ja kõhukinnisuse vastu; nendega võib pesta silmi, siis ei hakka külge haigus, ning peale selle kergendavad nad sünnitamist. Arhiiviandmete kohaselt usuti ka külmtõve (Simuna), langetõve (Simuna), paistetuse (Vändra), hambavalu (Kõpu) puhul pilvetükist abi saavat. Soomes 
kasutatakse pilvetükke ravimina põletuste, harvem pistete, silmahaiguste, mõhnade ja löövete puhul, sisehaiguste puhul söödi pilvetükist valmistatud kakku. Pilvetükk on Soomes hea ka profülaktiliselt: silmad ei haigestu, kui pesta neid äikese ajal alla sadanud pilvetükiga (Manninen 1929: 25-27).

Eestis usuti, et pilvetükid põhjustavad marutõbe, millest hoidumiseks maetakse nad maha (Loorits 1949: 437). M. J. Eisen teatab: "Kui koer niisuguse ära sööb, läheb ta hulluks" (Eisen 1926: 59). Rahvaluuletekstidest selgub, et pilvetükkide söömise tagajärjel on usutud erinevate loomade hullumist, põhiliselt on nimetatud koera.

Võibolla sisaldavad pilvetükid hallutsinogeenseid aineid, millega seletuks uskumus, et nad marutõbiseks või hulluks teevad. Erast Parmasto teatel (suuline) ei ole limaseente teatud toksilisus võimatu, kuigi spetsiaalselt polevat seda uuritud. Teatud limaseente hallutsinogeensus seletaks pilvetükkide arvatava taevase päritolu: seen, mille vahendusel kogetakse ebatavalist, ei saa pärineda maisest keskkonnast. Eeldatava kujutelma kinnistumisele võis kaasa aidata pilvetükkide ravitoime.

Nimetada võib seega pilvetükkide erinevaid funktsioone: ühelt poolt tarvitatakse pilvetükke ravivahendina, teiselt poolt põhjustavad nad aga marutõbe või hullust. Lisaks seostub nendega rahvusvaheline motiiv hunte toitvast patroonist: "Kui hundid palju ja tihti uluvad, siis tähendab see, et nad Jumalalt toitu küsivad, misjärel neile pakse pilvetükke alla visatakse, et nad neid sööksid ja nendega endal hinge sees hoiaksid" (Boecler \& Kreutzwald 1854: 122). "Kui hundid uluvad, visatakse neile taevast nagu seebitükid" (ERA II 55, 578/9 (18) < Martna khk - R. Põldmäe (1932)).

Pilvetükke kasutati mitmesuguses maagilises tõrjes. Eesti pärimuses on lugu, milles Kalevipoeg, aga ka Kalevi naine tulekahju puhul pilvega appi tuleb ja sadu pilvest tulekahju kustutab (Eisen 1919: 112; 1926: 60). Soomes usuti pilvetükkidega võivat kustutada koguni tulekahju, kui sellega ümber tule käia või selle vett tulle heita. Võib oletada kunagist eesti traditsiooni geneetilist seost soome uskumusega pilvetükkidest kui maagiavahendist, mis meil on aja jooksul kadunud.

Enne nägime, et arvamus, et need seened taevast päritolu on, annab neile üleloomulikke omadusi. Analoogne võib olla ka siinkirjeldatud seene tulekahjuvastane funktsioon: vihm on taevast päritolu ja kustutab tuld, kusjuures kehtida võib siin post hoc printsiip sakraalsemal määral kui tänapäeva inimene teaks oletada. Ilmari Manninen kirjutab: "Äikesepilves on tule vägi, see on kõige võimsam tuli, seepärast võib äikese ajal maha sadanud pilvega tavalist tuld ohjeldada. On tarvis vaid pilvetükiga ümber tule käia ja pritsida pudelist vett tulle" (Manninen 1929: 25-27).

Lõpetuseks küsimus, kas vanarahvas oskas näha ühist limaseente ja tavamõistes seente, st kübarseente vahel ja kas seosed kahe seenerühma vahel olid üldse teadvustatud. Enamik seeni on oma rahvapärase nimetuse saanud kasvukoha järgi, näiteks kaseseen, kuuseseen, männiseen, või viitab nimetus mingisugusele omadusele või eripärale: tatikas, võiseen. Tihti on tegu ka laenudega: puravik, krust, riisikas, mürkel. Pilviku kohta ei kehti aga ükski neist kriteeriumidest. Nimetus on etümoloogiliselt seotud sõnaga pilv. Pilvikut tuntakse pilveseenena (Saareste 1958: 761) ja taevaseenena. Võrreldagu seda uskumusega pilvedest kui seentest - taevas seenetab. Kui pilvetükid on taevast päritolu, on seda ka muud seened: rahvauskumuste kohaselt külvatakse taevast seeni ehk seeneseemet. Aga see jutt läheks juba põhiliselt kübarseente valdkonda. 


\section{Kirjandus}

Boecler, J. W. \& Kreutzwald, Fr. R. 1854. Der Ehsten abergläubische Gebräuche, Weisen und Gewohnheiten von Johann Wolfgang Boecler. Mit auf die Gegenwart bezeiglichen Anmerkungen beleuchtet von Dr. Fr. R. Kreutzwald. St. Petersburg. Eisen, M. J. 1919. Eesti mütoloogia. Tartu. Eisen, M. J. 1926. Eesti mütoloogia IV. Eesti vana usk. Tartu.

Hurt, J. 1899. Eesti astronoomia. Tartu.

Kastanje, V. 1995. Puugipask - Eesti Loodus. Nr. 2, 1k. 48-49.

Loorits, O. 1926. Liivi rahva usund I. Tartu.

Loorits, O. 1949. Grundzüge des estnischen Volksglaubens. I. Lund.

Manninen, I. 1929. Pilvi - Virittäjä. Nr. 33. Helsinki, s. 25-27.

Parmasto, E. 1987. Hundipiim. Eesti Loodus. Nr. 6, 1k. 368.

Parmasto, E. 1988. Mis see on? Eesti Loodus. Nr. 5, 1k. 321.

Saareste, A. Eesti keele mõisteline sõnaraamat. I. Stockholm. 